\title{
A PSICOLOGIA DO EGO DE ERNST KRIS E SEU LEGADO PARA \\ A“PSICANÁLISE DA ARTE"1
}

\author{
Gustavo Henrique Dionísio
}

Resumo: Trata-se de discutir a importância da psicologia do ego no que diz respeito à reflexão psicanalítica acerca da experiência estética. Centrando-se no trabalho inaugurador de Ernst Kris, o artigo pretende apresentar certas bases de seu pensamento, sugerindo, no entanto, uma leitura que recoloca a questão da sublimação como destino pulsional e não como mecanismo de defesa - no interior da articulação arte-psicanálise, fenômeno que atravessa o pensamento analítico desde os seus primórdios.

Palavras-chave: Psicologia do ego. Psicanálise. Estética. Metapsicologia.

Qualquer reescrita das relações entre arte e psicanálise não pode ignorar o Psychoanalytic explorations on art, texto de importância histórica que viria a se tornar objeto de reconhecimento nos anais da crítica de arte. Publicado em 1952 e cuja autoria coube a um dos principais discípulos da chamada segunda geração de psicanalistas, o livro consiste num esforço de construção intelectual que dá origem a uma verdadeira psicologia da arte. No entanto, para seu autor - Ernst Kris -, a despeito da urgência teórica que as investigações sobre o estético demandam, a

1 Este artigo é resultado parcial de uma pesquisa de doutoramento, concluída em 2010, no Instituto de Psicologia da USP, sob a orientação do Prof. Dr. João Augusto Frayze-Pereira. 
contribuição da psicanálise só pode ser medida se levar em conta as diferentes técnicas de sua clínica. No entendimento geral de Kris, o que mais interessa à investigação psicanalítica da arte seriam as determinantes que configuram o eu-artístico, isto é, quais seriam as condições psíquicas que permitem ao eu o exercício do processo criativo.

Cabe recordar que, antes de praticar a atividade psicanalítica, Kris exercia a função de historiador da arte e era um dos mais reconhecidos especialistas na Glíptica do Renascimento. Frequentador dos cursos de Dvoràk e de Schlosser em Viena, chegou a se tornar o encarregado do departamento de escultura no Museu de História da Arte da capital austríaca. Mais tarde esposaria a filha de um amigo de Freud, e, aproximando-se dele, empreenderia uma análise em 1924. Perseguido pelo III Reich, Kris encontra morada em Londres, num momento em que seus trabalhos já eram relativamente bem conhecidos fora de seu país; terminada a guerra, migra em definitivo para os Estados Unidos, onde começa a lecionar em diversas instituições.

Aproveitando a ocasião do ensaio para introduzir os pressupostos essenciais da chamada psicologia do ego - derivação conceitual que ele assumirá como leimotif do trabalho de interpretação - e, na esteira de Freud, Kris considera em "A contribuição da psicanálise e suas limitações" que a repetição de certos temas, observada inegavelmente no decorrer da história, deve possuir sempre uma explicação psicológica. Leia-se:qual a frequência, como isso se dá e quais as variações surgidas? São as perguntas a serem feitas pelo leitor. No seu entendimento, o estudo aprofundado da história da arte nunca pode ser realizado fora do conjunto mais amplo da comunicação humana, sobretudo na medida em que a edificação de qualquer discurso acaba inevitavelmente sendo atravessada pelos elementos que o constituem: mensagem - transmissão - recepção.

Citando Scharpe e refletindo a respeito da singularidade das escoIhas da humanidade, Kris (1968) acredita que o

\begin{abstract}
material psicanalítico permite-nos avaliar a atuação simultânea de fatores que levam um indivíduo a pintar, outro a dançar, escrever ou compor músicas. Às vezes, até mesmo generalizações mais amplas são possíveis; acreditamo-nos aptos a dizer por que determinada pessoa prefere a ação, outra a contemplação ou a especulação, por que este - com predisposições aparentemente semelhantes - devota sua vida à ciência enquanto outro à arte. (p. 15)
\end{abstract}

\title{
Modus operandi
}

Sob esse ângulo, os estudos de psicanálise aplicados à arte devem contemplar o exame de dois elementos centrais: a infância e/ou a adolescência do artista e as condições do meio sob as quais surge uma determi- 
nada criação (ou poética). ${ }^{2}$ O método consiste em estudar a"evolução do ego não apenas em relação a seus conflitos típicos, como também na medida em que suas capacidades e funções superam os conflitos e adquirem autonomia" (Kris, 1968, p. 18). Com a vantagem da não divisão entre forma e conteúdo, já que existem ações esteticamente organizadas entre um e outro, segundo ele, seriam três as psicanálises possíveis no contexto da aplicação dos conceitos freudianos: a psicanálise do estilo, a da expressão e a da imaginação criadora.

Evidentemente, cada uma delas exige recortes distintos. Grosso modo, a psicanálise do estilo é aquela que almeja interpretar o próprio curso da história da arte: conforme a teoria de Kris (1968), na medida em que "nenhum artista é independente de seus predecessores e modelos", ele sempre fará "parte de uma tradição específica", operando "dentro de uma determinada problemática" (p. 19). A da expressão, por outro lado, seria a forma com a qual esse estilo se individualiza, e nessa medida a ele ligada - o que configuraria um tipo de análise à la Leonardo, de Freud. Por fim, a psicanálise da imaginação criadora procuraria dar conta do aspecto antecipatório da atividade de produção artística: como o próprio Freud sugeria, em muitos casos os artistas chegam a verdades psicanalíticas antes mesmo dos analistas. Interessa, desse modo, investigar o "talento introspectivo" que permite chegar a tais conclusões. Mas para tanto se exige, em termos complementares, que se crie uma metapsicologia específica do processo criador. De acordo com Kris, afinal, assim como o sonho revela o funcionamento de um determinado processamento mental,é também possível admitir a existência de um mecanismo paralelo de processamento de arte.

Com respeito às operações psíquicas, a relação entre id e ego se concatenaria não somente por meio da satisfação das pulsões na direção do primeiro (id) para o segundo (ego) - aliás, trata-se de relações de compromisso indispensáveis ao funcionamento do aparelho psíquico. $\mathrm{O}$ caráter mais polêmico dessa teoria alude ao fato de que o ego teria o poder de controlar, na sua maior parte, a ação dos processos primários. Desse modo, o que desponta no sonho como sobredeterminado surgiria na arte como expressão máxima da "multiplicidade de significados" que é oriunda da experiência estética. O ego teria, portanto, autonomia para controlar o movimento que vai da inspiração à elaboração, atuando como mediador de equilíbrio entre processo primário e processo secundário.

Sob a égide do narcisismo, que leva o autor a entender o ego "não como uma série de funções isoladas mas como uma organização psíqui-

2 Luigi Pareyson (1997) indica distinções claras entre poética e estética. É comum tomarmos uma pela outra, ele considera, mas a diferença essencial é que a primeira deve ser compreendida como programa de arte, enquanto à segunda cabe a tarefa de produzir categorias gerais sobre o universo do artístico. 
ca" propriamente dita, sua psicologia irá se aprofundar, a partir de um método de investigação estrutural, nas funções que os mecanismos de defesa do eu exercem no movimento da prática analítica. Investindo mais na técnica que na teoria, essa psicologia se concentra na exploração ordenada dos mecanismos defensivos, visando estimular uma maior acuidade de adaptação do indivíduo ao meio que o circunda, de modo a fazer com que esse indivíduo se torne cada vez mais consciente de seu próprio funcionamento mental.

Nesse sentido, não"somente a Psicologia do Ego ampliou extensamente o escopo da terapia psicanalítica", conforme declara o psicanalista (Kris, 1968, p.17), como também teria provocado impactos na técnica freudiana direcionada às neuroses, corpo privilegiado de sua atuação. Tratase, no que concerne à terapêutica, de ampliar ao máximo possível o potencial de controle egoico: conquistado a duras penas ao longo do processo de desenvolvimento psíquico, ${ }^{3}$ o eu se tornaria a engrenagem fundamental da organização mental, vis-à-vis aos conflitos oriundos da experiência estética.

Mas não é possível referir à teorização de Kris sem deixar de mencionar que o principal objetivo das pesquisas de Heinz Hartmann - seu parceiro de pesquisa - era encontrar possibilidades mais bem-sucedidas de desenvolvimento da instância egoica. De acordo com Hartmann, todo e qualquer meio (social ou natural) exige que o indivíduo se depare com um aglomerado de acomodações adaptativas; nessa medida, é tarefa da psicologia estudar a estimulação de maiores cargas de fortalecimento do ego em virtude de um melhor desempenho de suas unidades funcionais. Em terapia, por exemplo, porções inatas acabariam se desenvolvendo progressivamente, tornando-se mais disponíveis tanto às pulsões (o psíquico) quanto à anatomia (o orgânico). Há, aqui, a urgência de bons ajustamentos na relação do indivíduo com seu ambiente, e assim o equilíbrio estrutural das instâncias acaba promovendo funções sintéticas de um ego estruturado (Blanck, 1983, p. 39).

Olhando mais de perto, no entanto, é como se Kris e seus colaboradores tomassem o "Wo Es war, soll Ich werden" das "Novas Conferências em Psicanálise" como um axioma da irreversibilidade de trocas entre o eu e o isso. Essa "fidelidade quase canina" da escola (Mezan, 2002, p. 189) não autoriza certificar, contudo, que em Freud o eu seja o senhor de todo o processo de criação artística, tendo então a primazia, ${ }^{4}$ nesse ínterim,

3 Encontramos um exemplo deste processo num comentário de Kris ao texto sobre "a piada", de Freud. A risada estaria para a regressão assim como o sorriso para o triunfo do ego, segundo Kris (1968, pp. 170-181).

4 Um comentário simples de Radmila Zygouris pode servir perfeitamente:"o Eu freudiano é intrapsíquico", afirma a autora,"é um puro conceito. Não é um elemento retirado da observação". Mas ele "só se sustenta em relação aos dois conceitos que são o isso e o supereu, movendo um campo de forças que se exerce sobre ele". 
sobre o isso. Se a interpretação se dirige ao eu e não ao isso, como afirma o autor de Lenda, mito e magia na imagem do artista, a investigação psicanalítica das artes só poderia encontrar vazão por meio dos processos de identificação e, dessa maneira, a partir de uma relação direta com a teoria da sublimação, nesse caso entendida exclusivamente como mecanismo de defesa. Por essa razão, a atividade sublimatória, ao lutar contra a impossibilidade "de operar uma dessexualização completa", acabaria se transformando "numa simples formação reativa" (Gagnebin, 1994, p. 19). Ora, não é exatamente isso o que acontece, a rigor, dentro da teoria freudiana: a sublimação, ainda que venha servir a uma melhor adaptação do eu, funcionaria antes como destino para satisfazer as pulsões (Trieb) sexuais. ${ }^{5}$

Em relação à arte, a conclusão de Kris é clara: essa necessidade do emprego extra-analítico seria algo inseparável à construção mesma da psicanálise, tal como ela teria nascido a partir de diversas influências (e descobertas) advindas de outros campos de pesquisa, ${ }^{6}$ o que não é muito diferente do modo de trabalhar do próprio Freud, como se sabe."Não se trata de transformar a crítica [literária] numa análise psicológica", escreve em um artigo de 1948 para o número XVII da Psychoanalytic Quarterly, "mas sim aplicar a nova metodologia [a psicanálise] a serviço da crítica" (Kris, 1968, p. 208, itálicos nossos).

\section{Sublimação ou formação reativa? Torções freudianas}

Para complicar um pouco mais as coisas, deve-se reconhecer que essa associação direta entre sublimação e formação reativa teria bases no próprio pensamento de Freud - embora não se possa dizer que ele a autorize de maneira cabal. Nessa conjuntura, a formação reativa seria entendida fundamentalmente como"transformação no contrário", segundo o Freud (1913/1996) de "O motivo dos três cofres", (p. 314), por exemplo. Em 1915 ele chegaria mesmo a homologar os destinos pulsionais como estratégias de defesa egoica. Com efeito, há, em Freud, uma enorme ambiguidade com relação à demarcação do processo sublimatório.

As contradições são notórias desde o texto sobre da Vinci, como é bem sabido, e perduram ao longo de toda a obra, aí incluídos os artigos sobre a metapsicologia (Freud, 1996/1910, pp.74-75; Laplanche, 1989, pp.

5 Há um exercício militante de crítica feita por Lacan à ego-psychology. Seu desacordo pode ser lido explicitamente no famoso ensaio sobre "O Estádio do Espelho como formador da função do Eu" (Lacan, 1999; Roudinesco, 1994).

6 Charles Hanly (1997) concebe exatamente a mesma ideia com relação ao pensamento extraclínico, muito provavelmente na esteira de Kris. 
22-23). Entre o evitamento e o destino,"sob certo aspecto ela é uma defesa contra as pulsões sexuais"; sob outro, concomitantemente, a sublimação também seria "uma possibilidade de satisfazê-las" (França Neto, 2007, p. 33). Para sublimar, de qualquer modo, é necessário que certas mudanças da matéria psíquica - que ocorrem ao longo de toda a sua dinâmica escapem ao recalque. $\mathrm{O}$ eu, no entanto, aqui pode apenas mediara situação: como, afinal, se poderia escapar à repressão, se o eu é justamente uma das consequências lógicas do processo de recalcamento? No que pertence ao arsenal defensivo do eu, na verdade a sublimação "não garante nada, não protege de nada", se concordarmos com André Green;ela apenas permite formas de obtenção de prazer de um modo, por assim dizer, "mais civilizado", não sendo capaz de suprimir outras modalidades "mais brutas" (Green, 1993, p. 322) de satisfação.

Em "O eu e o isso", Freud escreve primeiro que

Se esta energia de deslocamento é libido dessexualizada, é licito chamá-la também de sublimada, pois seguiria perseverando segundo o propósito principal de Eros, o de unir e ligar, na medida em que serve à produção daquela unidade na qual - ou por oposição à qual - o eu se distingue. Se incluímos os processos de pensamento, em sentido lato, entre esses deslocamentos, então o trabalho do pensar - este também - é satisfeito por uma sublimação de força pulsional erótica. (Freud, 1923/1969, p. 46, tradução nossa)

Não obstante, logo na linha seguinte, lê-se:

Vemo-nos aqui de novo diante da possibilidade já mencionada de que a sublimação se produza regularmente pela mediação do eu. Recordamos o outro caso, em que esse eu faz tramitar as primeiras (e por certo também as posteriores) investiduras de objeto do isso, acolhendo sua libido no eu e a ligando à alteração do eu produzida por identificação. (Freud, 1923/1969, p. 46, tradução e itálicos nossos)

Extraordinária ambivalência. Nesse momento, em função da teoria sobre o narcisismo, na qual ocorre o reinvestimento no eu como objeto de satisfação, identificação e sublimação são vistas praticamente como sinônimos. Além disso, o pressuposto de que ocorra a máxima dessexualização do conteúdo libidinal traz problemas ainda maiores: se se trata, com efeito, de que seja a libido a energia que move as pulsões sexuais, como seria possível dessexualizá-la? A "espiritualização" ou a idealização ficam, portanto, como resposta? Se sim, é possível considerá-lo somente a princípio, pois a ação de se "espiritualizar" ou de se "idealizar" sobre alguma coisa é uma saída cuja decorrência imediata vai de encontro à "desmaterialização", ou seja, muito longe de algo da ordem "material", o que se traduziria numa espécie de ausência de obra e não em sua criação. 
Tampouco a hipótese que sustenta uma "inibição de meta" poderia desfazer a ambiguidade, já que "a sublimação nunca pode tramitar se não houver uma certa porção de libido",como Freud declararia na XXII de suas "Conferências Introdutórias à Psicanálise" (1916-1917/996, p. 315). Nesse sentido, o melhor recurso talvez fosse compreender a sublimação como uma forma de metaforização da energia libidinal.

Afora considerarmos que o pensamento de Freud seja tão lacunar a esse respeito, antes o texto não deixaria dúvidas quanto à função de destino pulsional a ser cumprido pelo trabalho sublimatório. De acordo com a letra freudiana, entre o eu e o isso,

\footnotetext{
A transposição assim cumprida de libido de objeto em libido narcísica acarreta, manifestadamente, um abandono das metas sexuais, uma dessexualização e, portanto, um tipo de sublimação. Mais ainda, aqui se coloca uma questão que merece ser tratada a fundo: não é esse o caminho universal para a sublimação? Não se cumprirá toda sublimação pela mediação do eu, que primeiro muda a libido de objeto em libido narcísica, para depois dar-lhe outra meta? (Freud, 1923/1996, p. 32, tradução nossa)
}

Ora, em se tratando de uma teoria que parte da estruturação egoica como organizadora e centralizadora da atividade psíquica, nada mais coerente para Kris do que realizar uma exportação da teoria freudiana da criação guiado por esse conceito de sublimação. $O$ que aponta não ser nenhum absurdo, uma vez que o capítulo sobre a sublimação, que deveria compor os artigos de metapsicologia, de fato nunca veio a ser escrito por Freud, abrindo terreno para que a psicanálise contemporânea pudesse indicar algumas correções. No que tange a seu aspecto dinâmico, Kris compreendia o mecanismo sublimatório segundo a batuta mais rigorosa da doutrina freudiana: para ele, a sublimação também funcionava a partir da ação combinada entre as diferentes exigências de satisfação originadas no isso, de tal modo que, por meio da flexibilidade de repressão própria no artista, torna-se possível a transformação dos conteúdos inconscientes em matéria artística.

De maneira geral, o processo envolveria essencialmente duas operações: um "deslocamento inicial de energia psíquica", no qual a energia que parte da libido será transformada, após a passagem pelo recalcamento, em objeto a ser apreciado, quer dizer, num objeto que em princípio seria publicamente inaceitável e que deixa de sê-lo por conta da transformação; a isso se soma uma "neutralização" dessas mesmas energias libidinais, cujo rebaixamento se dá, de maneira paradoxal, por meio da "agressivização"7 do conflito entre o desejo (o sujeito, mais precisamen-

7 A concepção foi inventada por Kris e parece se remeter à ideia de uma transformação do "teor psíquico" das cargas energéticas provindas do isso. 
te) e o objeto. Cada operação tem outra como consequência, assim como acontece na origem de uma fusão com a descarga de energia pulsional ou, em especial, no surgimento de alterações das camadas psíquicas organizadoras do ego.

A dinâmica psíquica da sublimação deve ser debitada,como se pode constatar, sob os encargos do eu-artístico, uma vez que a operação ocorre no psiquismo criador. Seu sucesso ou fracasso dependerão, do ponto de vista de Kris (1968), do maior ou menor grau de autonomia que o ego do artista possui em relação à sua produção, ou melhor, até onde "sua atividade está desembaraçada do conflito original que voltou seu interesse e talento em determinada direção" (p.25).É conforme a largura desse distanciamento que um determinado artista conseguirá se destacar numa determinada virada histórica. Suas conquistas estarão sujeitas à confluência exata entre as características individuais e as exigências de época que no caso ele venha a satisfazer.Impõe-se, nessas circunstâncias, um processo inequívoco de comunicação que vai "do particular ao geral" (p.27).

Mas essa confiança na autonomia egoica acaba se tornando matéria de graves discussões. Ela teria surgido com a Psicologia do Ego visando enunciar uma certa"autossuficiência" das funções de autoconservação, de acordo com a revisão do conceito de sublimação feita por Laplanche. Haveria ali, como se verifica em uma de suas Problemáticas, uma confusão entre o que é fonte pulsional e o que é autoconservação, entendidas como sinônimos. "Se for adotada essa interpretação restritiva", declara Laplanche (1989), "vemo-nos conduzidos à ideia de uma anterioridade" (p. 52) perene, quase incontornável. O ponto extremo dessa posição é encontrado"numa corrente da psicanálise americana em que essas funções autônomas (entenda-se, as funções de autoconservação não sexuais) são pura e simplesmente atribuídas ao ego - ele próprio um 'ego autônomo'"(p. 52, itálicos nossos).

Nesse sentido, não é por acaso que Kris aposta suas fichas, no que diz respeito ao estético, numa função relacionalcomunicadora à qual todo o conjunto da experiência com a arte estaria subordinado; com efeito, ele nunca abriria mão dessa tese. Para prová-la, propôs um experimento quase doméstico: sugeriu, a um grupo de amigos, a leitura de Frederick Rolfe, escritor de destaque no início do século XX, esperando deles uma reação psicológica específica - a que ele mesmo havia sentido, um misto de"fascinação e repugnância", ambivalência que viria a se confirmar posteriormente com os colegas leitores.

Sobrariam, contudo, dois sujeitos que não compartilhavam da mesma opinião e, no caso desses, apenas um dos sentimentos se mantinha. $O$ primeiro alegava estar extasiado diante da leitura, enquanto o outro apresentou reações de ojeriza após a experiência. Como entender a reação anômala? Nessa situação, explica o pesquisador, as reações tornaram-se 
explícitas em função de sua natureza pessoal, de modo que refletiriam o prolongamento (ou a neutralização, melhor dizendo) das fantasias num ego que tentava compensar uma "ação masturbatória" (Kris, 1968, p. 27), fato que por sua vez leva à verdadeira genealogia inconsciente da resposta. (Cabe mencionar, de passagem, que Kris conhecia a vida pregressa dos participantes e as associou aos resultados dessa pequena pesquisa particular).

Ao interpretar a cena, decidiu de qualquer modo pelo caráter conservador das imagens - conservador porque, na maior parte dos casos, a reação acabou preservando o eu de uma realidade que porventura seria vivida como "insuportável", uma experiência evidentemente inconsciente. Assim, para o aparelho, aquelas imagens funcionaram como uma modalidade de mecanismo de defesa "criativo", haja vista o emprego narrativo exercido por elas na organização psíquica de cada um dos participantes de sua investigação. Nada é mais egoico que buscar afastar o conflito de alcance; o objetivo máximo da defesa é deixar terreno livre para as descargas decorrentes. Em termos gerais e em relação à arte,"sua mensagem é um convite [que parte de] uma experiência mental comum", chegando enfim a "uma experiência de natureza absolutamente única" (Kris, 1968, p. 34). Sob os auspícios da função comunicativa, a imagem ocuparia "um lugar entre o gesto e a palavra", ainda que não pressuponha "a presença da pessoa a quem se dirige" (p.44).

Deve-se notar, no conjunto da reflexão de Kris, que por comunicação ele entende o mesmo que representação, e isso num duplo sentido: num primeiro plano, quando sugere que as artes se encerrariam em uma função substitutiva à realidade (seja ela natural, biológica ou mesmo psicológica); num segundo, na própria ação que o artista executa para recriar a natureza, em vez de imitá-la ou reproduzi-la. Sua teoria a respeito do destinatário da arte é praticamente idêntica: o receptor também deverá perpassar certos estádios de funcionamento psicológico para que então adentre a experiência estética. Após o reconhecimento prévio de motivos - determinados assuntos podem ser relacionados a traços de memória familiares -, esses virão a se tornar parte do espectador. É sabido o quanto a percepção humana é afetada pelo mundo das imagens; ao eu, portanto, só restaria empregar os aparelhos perceptivo e psíquico a fim de encontrar soluções mais adequadas que venham a se inscrever no corpo do indivíduo. Kris propõe a hipótese de que no final dos procedimentos o destinatário será assaltado por uma indagação profunda sobre os efeitos do percebido, a ponto de se sentir acometido pelos mesmos processos de criação que invadiram o artista no momento da concepção da obra. É como se o espectador, ao vê-la, se tornasse dela um coautor.

Construindo teorias que investigam os efeitos que a obra provoca no espectador, o trabalho de Kris não deixaria para trás a discussão sobre a catarse aristotélica, essencial à teorização do mecanismo identificató- 
rio. É assim que essa concepção, ponto de ancoragem do conceito de representação, seria por ele reinterpretada a partir do vocabulário psicanalítico.

\section{Representação e catarse, estéticas ${ }^{8}$ da empatia}

Funcionando na ocasião como mecanismo de regressão do ego, o efeito catártico é aquele que assegura o jogo de ilusão estética, e, de acordo com Kris, quando se fala em arte se fala em ilusão. Sua função é, primordialmente, proteger o eu, o que explicaria, por exemplo, a existência de um evento, tão comum quanto enigmático, como o sentimento prazeroso ligado ao desagradável (o caso da tragédia seria, nessa perspectiva, o mais evidente pelo alto nível de angústia que suscita no espectador). A intensidade do desejo criada quando o sujeito se encontra diante de um objeto correlato faz com que ele se mova segundo a necessidade de autoesgotamento própria do princípio de satisfação. Contudo, a experiência com a arte determina que esse sujeito repita, mas agora de maneira ativa, aquilo que antes fora vivenciado passivamente, ainda que nesse exato momento saiba que o brinquedo - o jogo - é apenas um brinquedo. No tocante à obra freudiana, percebe-se o quanto essas teses se amparam em "Personagens psicopáticos no palco", onde Freud (19051906/1996, p. 277) aludia à identificação ao herói como canal privilegiado de trocas entre as polaridades passivo-ativo.

Nessa visada, a psicologia do artista se aproximaria da psicologia do ator e, por extensão, das catexias chamadas identificatórias:em certas casualidades, $\mathrm{o}$ ator que representa um papel pode perceber que vive uma vida equivalente à de seu personagem e,"se ele deseja dar um outro final à peça,é porque deseja corrigir alguma coisa na sua'vida'" (Kris, 1968, p. 38). Não se supõe, evidentemente, que a teoria acredite que o ator venha a confundir sua vida com a da ficção:quando Kris se refere à "pessoa do artista" está se remetendo à sua "personalidade artística", nada mais; ainda assim, nem por isso ficamos sem a impressão de que, pela escolha de seus exemplos, nosso historiador-psicanalista ${ }^{9}$ procuraria erigir uma ponte sem mediações entre caso clínico e obra de arte.

Ainda que munido desses reparos, não é minha intenção defender a redução da escola americana às limitações de sua teoria sobre a aplica-

8 Aqui é precisamente a noção de estética (e não de poética) que desejo utilizar, como assim a concebe Pareyson (1997).

9 Deve-se mencionar que as teorias de Ernst Kris tiveram papel determinante no pensamento de um historiador da arte tão importante como Ernst Gombrich, a quem me remeto logo a seguir. Kris construiu, é certo dizê-lo, uma boa parte de categorias que influenciariam a disciplina de História da Arte até o momento atual. 
ção. No "tocante à interpretação", escreve a esse respeito Renato Mezan, "é necessário dizer que a ego-psychology seguiu à risca as pegadas da psicanálise vienense". Ainda de acordo com Mezan (2002), essa disciplina que se firmaria como Psicologia do Ego foi "o ramo da psicanálise que menos se afastou do vocabulário de Freud e de sua concepção geral da psique, do desenvolvimento mental e do processo terapêutico."Tomadas as devidas precauções, isso não significa, por outro lado, que devamos compartilhar ou reproduzir suas conclusões sem questioná-las, isto é, também acreditando "que a sua era a única e verdadeira psicanálise" (p. 189).

Ao fim e ao cabo, talvez o grande limite desse método de recepção resida no uso que a ego-psychologyfez da Teoria da Empatia (Einfühlung) de Lipps e Worringer. Nesse contexto, a noção de empatia teria sido"confundida com uma comunicação intersubjetiva imediata", como indica a esse respeito Françoise Coblence, perdendo-se num processo de identificação afetiva cujo movimento "constituirá um suporte curativo". De sua parte, Julia Kristeva aponta quais seriam as consequências diretas de uma tal apreensão: dizer que se trata de uma "intersubjetividade" é o mesmo que declarar a reificação da experiência analítica, reduzindo o fenômeno da transferência à simples empatia entre dois psiquismos. Se existe algum nível de intersubjetividade em psicanálise, conclui Kristeva, é somente na medida em que ela se traduza em categorias tão negativas quanto "transsubjetividade" ou "horizontalidade do transindividual",assim como foram propostas por Lacan (Kristeva, 1997; Zygouris, 2006).

O maior risco da posição empática seria o de se apoiar "na concepção de um sujeito reunificado, para o qual o recalcado não terá nenhuma especificidade" (Coblence, 2005, p. 26). Assim, as reflexões estéticas da Psicologia do Ego disfarçariam uma latente má compreensão: para além do simples sufocamento do recalque, pode-se dizer que a concepção original de Lipps teria aberto todo um espaço de experimentação estética, ambiente que pôde privilegiar saberes dirigidos ao modo como os objetos de arte se apresentam ao espectador; em outras palavras, seu surgimento traria consigo uma verdadeira teoria da recepção. Com efeito, a empatia se inicia no mecanismo de identificação, embora não se reduza a ele: partindo do familiar, proporciona uma compreensão do que é "estranho como estranho" (Coblence, 2005, p. 46). Tomada à risca, a empatia não é, no vocabulário filosófico, o "sentir com" (Einfühlung) desejado por Ferenczi, e tampouco o"sofrer com o outro sem sofrer em si mesmo", ofertado pelas terapias humanistas mais contemporâneas. Importando-a ao campo psicológico, a empatia permitiria a existência da relação de transferência em análise e, desse modo, é ela quem abre espaço para uma escuta analítica propriamente dita.

Quando se compreende o conceito da ab-reação (catarse) via Psicologia do Ego, deve-se levar em consideração que é característico do ego garantir um controle o mais competente possível das descargas que 
evadem o sistema psíquico, mantendo concomitantemente uma relativa autonomia de ação diante das forças pulsionais que surgem na direção contrária. Ao final, o resultado seria conquistar um tipo de insight capaz de proporcionar total "liberdade para viver a experiência de maneira protegida", cuja decorrência promove um prazer duplo: aquele que surge como consequência da descarga de afetos, de um lado, e, de outro, o controle que o ego revigora e que assim, ao revigorar, ganha mais prazer a cada nova situação.

\section{Psicanálise e História da Arte}

A meu ver, as questões aí propostas ganham ainda maior proveito quando adentram o circuito das ideias sobre o estético. Em "A Psicanálise e a História da Arte", por exemplo, Ernst Gombrich sugere um sistema de construções históricas a ser elaborado diante da categoria chamada por ele de representação conceitual. Conforme o pressuposto de base, os paradigmas da pesquisa histórica deveriam se debruçar nas fórmulas"representacionais" que um determinado objeto possui, o que garantiria a certeza de que se está falando de um homem ou de uma mulher, de um cavalo ou de um cachimbo, nesse sentido. Assim, na esteira da psicanálise da arte de Kris, Gombrich acredita que toda atitude estética advém de um tipo específico de reação ou descarga: o "entendido de arte deseja identificar-se com o artista", declara, "precisa ser puxado para dentro do círculo encantado e partilhar seu segredo".Para ele, a arte só cresce -"evolui", em seus termos - em função do que produz enquanto novidade no interior de sua própria instituição, que é formada pelo triângulo "artista, público e contexto".

Nesse sentido, recepção estética e subjetividade estão aqui em profunda conexão. A respeito da Europa de Ticiano, por exemplo, comparada em relação à de Rafael, sua antecessora, Gombrich declara aos psicanalistas de Londres, em 1952, que

Não deve ter escapado aos senhores que dentro da esfera da pintura a relação estética ocasiona uma maior liberdade. Essa Europa, pintada para Filipe Il da Espanha, é sem dúvida mais abertamente erótica do que qualquer coisa que circulou antes. No entanto, o conteúdo erótico não é escondido nem imposto. É absorvido, por assim dizer, nesse processo estético de recriação, de troca de concessões. Podemos suspeitar de que um aumento dessa participação ativa, da atividade projetiva, vem acompanhado talvez de uma liberação de tabus convencionais. Mesmo o piedoso Rei da Espanha podia olhar para uma obra-prima do pincel como essa sem sentimentos de culpa, pois quem poderia negar que se tratava aqui de arte no seu mais alto grau? (Gombrich, 1999, p. 37) 
Em outras palavras, tais ideias nos levariam a entender que o historiador acredita que a arte seja um meio privilegiado para integrar, em virtude do que fabrica como "prêmio de realização estética", a pulsão e suas componentes agressivas? Nesse sentido, a saída encontrada por Rafael seria mais adequada porque ele consegue oferecer uma experiência visual que não é "nem escondida nem imposta" ao eu. Uma piada visual seria muito mais complexa que uma anedota verbal, e é assim que determinadas imagens precisam, para serem fruídas, não de uma "evolução da humanidade", como Gombrich (1999) conclui, mas do desenvolvimento de sua evocação perceptiva visual.

Com isso, o historiador recomenda uma sugestão lúdica para averiguar, por canais estritamente psicanalíticos, certas generalizações possíveis à experiência estética. Brincando com a conjectura de que as satisfações orais poderiam servir como modelo genético de explicação para o problema do prazer estético, Gombrich apresenta os fatos: no senso comum, quando entramos numa exposição, falamos a respeito do "gosto" que dedicamos à arte, o sabor de cada quadro etc., bem como somos capazes de discriminar, no íntimo de cada um, aquilo que em certa comida realiza satisfações mais primitivas, pois é através da alimentação que encontramos o seio materno, tal como, adiante, o treino das primeiras faculdades críticas ad hominem.

Retornando à experiência estética, sua metáfora culinária certificaria o equilíbrio de dosagens, sem o qual o alimento se tornaria insosso ou mesmo desprezível. Isso explica a sensação de mais-de-sedução que existe em certas obras de arte que, embora desejem atrair, acabam provocando repulsa por conta de seu gosto exagerado, um excesso de regressão e de passividade que exige do espectador. Para ilustrar, o famoso historiador sugere que o Impressionismo teria sido um verdadeiro divisor de águas entre dois modos de satisfação estética:"Podemos vê-lo como o ápice do progresso que conduz à equiparação cada vez mais estreita do símbolo pictórico às aparências, e como o começo de uma arte abertamente regressiva, o primitivismo" (Gombrich, 1999, p. 42). Não obstante, a pergunta que permanece sem reposta é se o Impressionismo divide o muro das compensações do gosto ou produz uma poética específica para chegar até aí.

Quando Picasso se transforma, isto é, faz das linhas cubo e dota suas personagens de sentimentos atraentes, "em termos psicológicos a coisa interessante não é o fato de ter ele feito o que estava mais ou menos na lógica da situação, mas o quanto teve de esforçar-se para escapar da maestria e do sentimento e satisfazer a demanda de mais atividade e mais regressão" (Gombrich, 1999, p. 42). Honestamente, o que importa, quando olhamos Picasso, não é o fato de que seu inconsciente esteja neste ou naquele trauma aí exposto, ou que ele tenha ultrapassado seu Édipo assim ou assado; interessa perceber, no entanto, que em seu momento 
Picasso"se acha numa situação em que seus conflitos particulares adquirem relevância artística. Sem os fatores sociais...o estilo ou a tendência, as necessidades privadas não podiam ser transmutados em arte"(p.43). Ainda no entendimento de Gombrich, se o gosto é de fato acessível à análise psicológica, isso não significa que a arte também o seja; e mesmo que o artista dependa dos símbolos, articulando-se àqueles que estão disponíveis em sua época, isso não é tudo: o que o artista faz deve ir além porque a "verdadeira obra de arte claramente realiza mais do que a satisfação de alguns anseios analisáveis" (p.44).

Por fim, e para não deixar nenhuma dúvida a respeito de suas filiações, Gombrich (1999) declara que é

\begin{abstract}
o ego que adquire a capacidade de transmutar e canalizar os impulsos do id, e uni-los nesses cristais multiformes de miraculosa complexidade que chamamos obras de arte. Elas são símbolos, não sintomas, de tal controle. É o nosso ego que, em ressonância, recebe dessas configurações a certeza de que a solução do conflito, a consecução da liberdade sem ameaça à nossa segurança interior, não está totalmente fora da apreensão da mente humana ambiciosa. (p. 44)
\end{abstract}

Uma das principais ideias que faz com que o historiador se aproxime de Ernst Kris (os dois almejaram escrever a quatro mãos um ensaio sobre a caricatura, o que não chegaria a se concretizar, diga-se de passagem) encontra-se, em minha opinião, na concepção de arte que compartilham. Entendido como efeito de reconciliação entre as diferentes pulsões, os dois consideram que o gosto seria uma espécie de integração, decorrente da maior ou menor capacidade de adaptação egoica conquistada pelo psiquismo; além do mais, Gombrich ratifica o interesse que a psicanálise demonstra pelos objetos de arte pertencentes a épocas muito anteriores ao momento contemporâneo, ainda que o texto a que venho me reportando aqui tenha sido publicado no início dos anos 1950.

Mas isso não é o bastante: segundo Gombrich, Kris teria sido responsável por toda uma renovação no debate sobre as reações psicológicas do espectador. Essa "interação entre o artista e o espectador", indica o historiador da arte, "é um fator muitas vezes esquecido. Sua formulação teórica do ponto de vista da psicanálise, devemo-la a Ernst Kris, que é meu guia e mentor nessas coisas". Ora, o caráter inaugural dessa psicologia da "atitude" estética, atribuída nesse caso ao psicanalista austríaco, impede que a compreendamos meramente como uma tentativa ingênua de teorização. Pois teria sido ele, ademais, "o primeiro a sublinhar o fato de que a emergência do que se poderia chamar a atitude estética com relação à pintura ocasiona um novo tipo de reação, ou, como ele mesmo diz, de descarga" (Gombrich, 1999, pp. 35-36). 


\section{Considerações finais}

Não obstante, é muito provável que essa aproximação à qual assistimos, cujo ponto de partida é o vetor da psicanálise aplicada e se completa na psicologia do ego, produza ressonâncias em historiadores da arte que cedem à vontade de acrescentar um substrato "humano" e menos "idealista" ao fenômeno estético, revelando a intenção de decifrar a gênese da criação artística por meio dessa abordagem. Na França, por exemplo, Rene Huyghe, antigo conservador do Louvre, assumia uma cadeira de Psicologia da Arte no Collège de France exatamente no mesmo momento em que Gombrich e Erwin Panofsky eram transferidos para Londres, assim como o próprio Ernst Kris "dava continuidade ao trabalho que iniciara em Viena junto a Freud sobre as relações entre Psicanálise e Arte", conforme atesta a pesquisa de Frayze-Pereira (2005, p. 33).

Entendendo a obra de arte como linguagem, Huyghe desejava propor uma teoria que desse cabo da interação entre os termos - arte e linguagem. Em "Psychologie des arts plastiques" - artigo publicado, a propósito, em uma revista de psicologia -, ele adverte que qualquer análise sistemática da imagem impõe muita atenção à consciência de “interdependência ativa",algo que existe entre a obra, seu tempo e suas invariantes, ou melhor, às "constantes psicológicas" que remontam a uma explicação mais tardia da "personalidade do artista" (Huyghe, 1993, p. 163, itálicos nossos). A insistente aproximação que vai da psicologia à arte deveria ser amparada, para o autor, menos pelo legado freudiano que pelas colaborações que Carl Gustav Jung reuniu em torno de sua psicologia do espírito coletivo:

Se os métodos demasiado sistematizados de certos psicanalistas freudianos estão a prescrever, a psicanálise, até onde o mais se ampliou, em particular por Jung, pode ajudar a determinar as imagens nas quais a repetição ou a analogia revela as preocupações mais íntimas e mais constantes do artista; suas mutações revelam aquelas de seu ser profundo. (Huyghe, 1993, p. 164)

E a respeito, por exemplo, das"dualidades"encontradas em Delacroix - seu objeto de estudo privilegiado - Huyghe observa que os traços contraditórios de sua arte estão também presentes em sua vida pessoal, de modo que a análise "de sua imaginação e de suas obsessões vêm a corroborar e esclarecer aquilo que já sabíamos das contradições de sua pessoa"... artística (acrescentaria de minha parte). Assim, a aproximação da psicologia à forma faz com que se esclareçam, uma diante da outra, psicologia e forma, no entanto sempre tendendo à psicologia do artista; para Huygue, existiriam equivalências simbólicas entre forma e vida, pois é no visível da obra que reside a natureza complexa do criador. Inconsciente e consciente só fazem sentido se se admite que, neles, possamos encontrar 
uma síntese que parta da própria composição, da sua singular fisionomia - estreita união entre psicologia coletiva e individual.

Cá para nós resta saber se as aproximações entre a psicanálise e a experiência com a arte ainda podem se ancorar em possibilidades egoicas de um sujeito a que poderíamos chamar de "estético", seja ele criador ou espectador. Ora, a expressão "psicanálise da arte", em si mesma, já quer dizer muita coisa: atesta um modo de trabalhar que encerra a experiência analítica numa simples aplicação do vocabulário freudiano ao fenômeno das artes. Sustentar o potencial do eu como um mecanismo privilegiado dos processos criativos não seria uma tentativa renovada de atrair, de maneira acrítica, as estratégias fechadas da aplicação para dentro de novos cenários?

\title{
Ernst Kris ego-psychology and its legacy to the "psychoanalysis of art"
}

\begin{abstract}
This article intends to discuss the importance of the ego-psychology towards the psychoanalytical interpretation of the aesthetic experience. Its focus is based on the Ernst Kris original work, therefore it intends to present certain basis of his aesthetical thinking. In this case, however, it will suggest one certain reading which emphasizes the problem of sublimation as a drive destination - and not as a defense mechanism - in within this relationship between art and psychoanalysis; hence, it brings out a phenomenon that crosses the psychoanalytical thinking since its first conception.
\end{abstract}

Keywords: Ego-psychology. Psychoanalysis. Aesthetics. Metapsychology.

\section{La psychologie du moi d'Ernst Kris et son héritage pour la "psychanalyse de l'art"}

Résumé: Le but de cet article est de discuter l'importance de la psychologie du moi à l'égard de la réflexion psychanalytique à propos de l'expérience esthétique. En tant qu'il met l'accent sur les premiers travaux de Ernst Kris, le texte essai de présenter quelques fondations de sa pensée, ce qui suggère, cependant, une lecture qui remet la question de la sublimation comme une funcion de destination pulsionnelle - et non comme un seul mécanisme de défense - dans la lecture psychanalytique de l'œuvre d'art ; enfin, cet-à-dire un phénomène qui traverse la réflexion psychanalytique depuis son début.

Mots-clés: Psychologie du moi. Psychanalyse. Estétique. Metapsychologie. 


\section{La psicología del yo de Ernst Kris y su legado para la "psicoanálisis del arte"}

Resumen: El trabajo visa discutir la importancia de la psicología del yo con respecto a la reflexión psicoanalítica sobre la experiencia estética.Centrándose en la obra inauguradora de Ernst Kris, el artículo trata de presentar algunas bases de su pensamiento, lo que sugiere, sin embargo, una lectura que pone la cuestión de la sublimación como una función de destino - y no como un mecanismo de defensa - en el arte, quiere decir, un fenómeno que atraviesa el pensamiento analítico desde su creación.

Palabras clave: Psicología del yo. Psicoanálisis. Estética. Metapsicología.

\section{Referências}

Blanck, G. (1983). Psicologia do ego. Porto Alegre: Artes Médicas.

Coblance, F. (2005). Les attraits du visible: Freud et l'esthétique. Paris: PUF.

França Neto, O. (2007). Freud e a sublimação: arte, ciência, amor e política. Belo Horizonte: Ed.da UFMG.

Frayze-Pereira, J.A. (2005). Arte, dor. Inquietudes entre estética e psicanálise.Cotia, SP:Ateliê Editorial.

Freud, S. (1996). Personajes psicopáticos en el escenario. In Obras completas (Vol. 7). Buenos Aires: Amorrortu. (Trabalho original publicado em 1905)

Freud, S. (1996). Un recuerdo infantil de Leonardo da Vinci. In Obras completas (Vol. 9). Buenos Aires: Amorrortu. (Trabalho original publicado em 1910)

Freud, S. (1996). El motivo de la elección del cofre. In Obras completas (Vol. 12). Buenos Aires: Amorrortu. (Trabalho original publicado em 1913)

Freud,S. (1996). El yo y el ello. In Obras completas (Vol. 19). Buenos Aires:Amorrortu. (Trabalho original publicado em 1923)

Freud, S. (1996). Nuevas conferencias de introducción al psicoanálisis y otras obras. In Obras completas (Vol. 23). Buenos Aires: Amorrortu. (Trabalho original publicado em 1932-1936)

Gagnebin, M. (1994). Pour une esthétique psychanalytique: I'artiste, stratège de I'inconscient. Paris: PUF. 
Gombrich, E. (1999). Meditações sobre um cavalinho de pau e outros ensaios sobre a teoria da arte. São Paulo: EDUSP.

Green, A. (1993). Le travail du négatif. Paris: Les Éditions de Minuit.

Hanly, C. (1995). O problema da verdade na psicanálise aplicada. Rio de Janeiro: Imago.

Huyghe, R. (1993).Psychologie des arts plastiques. Bulletin de Psychologie, 46(410). 163-166.

Kris, E. (1968). Psicanálise da arte. São Paulo: Brasiliense.

Kristeva, J. (1997). Pouvoirs et limites de la psychanalyse II: La révolte intime.Paris: Fayard.

Laplanche, J. (1989). Problemáticas III: a sublimação. São Paulo: Martins Fontes.

Lacan, J. (1999). Écrits (Vol. 1). Paris: Seuil.

Mezan, R. (2002). Interfaces da psicanálise. São Paulo: Companhia das Letras.

Pareyson, L. (1997). Os problemas da estética. São Paulo: Martins Fontes.

Roudinesco, E.(1994). Lacan: esboço de uma vida, história de um sistema de pensamento. São Paulo: Companhia das Letras.

Zygouris, R. (2006). Nem todos os caminhos levam a Roma. São Paulo: Escuta. 
Gustavo Henrique Dionísio, psicólogo, professor assistente do Departamento de Psicologia Clínica da Universidade Estadual Paulista - UNESP, Assis. Mestre e doutor pelo Instituto de Psicologia da Universidade de São Paulo - USP. Endereço para correspondência: Avenida Dom Antonio, 2100, Assis, SP, Brasil. CEP 19.800-000. Endereço eletrônico:gustavohdionisio@gmail.com

Recebido: 01/02/2011

Aceito:07/09/2011 